\title{
A snapshot of nurses' understanding, perceptions and comfort level of genomics
}

\author{
Leighsa Sharoff* \\ Hunter College School of Nursing, NYC, NY, USA
}

Received: June 18, 2021

Accepted: July 12, 2021

Online Published: July 25, 2021

DOI: $10.5430 /$ jnep.v11n12p1

URL: https://doi.org/10.5430/jnep.v11n12p1

\begin{abstract}
Objective: The primary aim of this study explored holistic nurses' self-perceived genomic knowledge, perceptions, attitude and comfort of genomics. A second aim compared results to previous findings of nurse educators and advanced degree practicing registered nurses' genomic knowledge utilizing the same survey instruments.

Methods: Design: Recruitment of participants, through the American Holistic Nurses Association (AHNA), was achieved via an anonymous Survey Monkey link of the Genetic and Genomic Literacy Assessment (GGLA) survey. The GGLA survey comprised three aspects: Self-Perceived Genomic Knowledge Survey; Perceptions and Attitudes about Genomics Integration into Nursing Practice Survey and the Comfort Level of Genomics Survey. Method: The GGLA survey link was made available via the AHNA newsletter.

Results: Holistic nurses $(n=41)$ self-perceived genomic knowledge level demonstrated a knowledge base gap in their comprehension and ability to explain genomic concepts to their patients. Majority of holistic nurses were significantly not comfortable with their genomic knowledge (90\% or greater). Comparison with nurse educators $(n=53)$ and advanced degree practicing registered nurses' $(\mathrm{n}=36)$ genomic knowledge provided additional insight.

Conclusions: A significant majority of nurses are unprepared to adopt genomics into their practice whilst experiencing a lack comfort and confidence. The global success of nursing practice resides with its' practitioners being fully informed and competent with all required competencies, especially if nursing is to remain prevalent within personalized healthcare.
\end{abstract}

Key Words: Genomic knowledge, Genomic perceptions, Comfort level, Holistic nurses, Nurse educators, Advanced degree nursing student

\section{INTRODUCTION}

All healthcare providers are required to be knowledgeable of genomic information in order to provide effective and personalized precision care to their patients, especially to those who have a genetically-based condition themselves or within their family. Understanding genomics, the study of the structure and function of the genome and its interactions with the environment, and genetics, the study of inheritance and variation is genetics, is an essential competency of all healthcare professionals. ${ }^{[1,2]}$ Nurses, as part of the integral healthcare community, necessitates remaining informed of this knowledge while integrating it into their patient-centered care and interactions. The continued success of nursing practice resides with its' practitioners being able to be fully informed, competent and comfortable with genetically-based conditions. However, research has shown that practicing nurses demonstrate deficiencies in genomic knowledge and skills. ${ }^{[3]}$ This study explored holistic nurses' self-perceived

${ }^{*}$ Correspondence: Leighsa Sharoff; Email: 1sharoff@hunter.cuny.edu; Address: Hunter College School of Nursing, NYC, NY, USA. 
genomic knowledge by answering the following questions: 1) What are holistic nurses' self-reported perceptions of their knowledge regarding genomics concepts and conditions; 2) What are holistic nurses' perceptions of the importance of integrating genomics concepts into the nursing practice; 3 ) What genetic concepts, conditions and topics are integrated into their nursing practice? And 4) Do holistic nurses' have prior education or training in genomics concepts, and are they comfortable integrating this knowledge in their practice? Furthermore, exploration of the results of this small sample of holistic nurses from the United States (US; $n=41$ ) self-perceived genomic knowledge, perceptions and comfort level will be compared to previous findings of nurse educators $(n=53)$ and advanced degree practicing registered nurses $(\mathrm{n}=36)$ genomic knowledge utilizing the same survey instruments. ${ }^{[4]}$

\section{BACKGROUND}

\subsection{Genomics}

The study of how genetic variants influences health and wellbeing has led to significant and transformative understanding for all healthcare providers, patients/families and societal communities as a whole. ${ }^{[5]}$ Since the completion of the international Human Genome Project and human genome sequencing, the genomic era has redefined personalized precision medicine. ${ }^{[6]}$ Foundational core minimum competencies define the knowledge and skills for all healthcare professionals (from pre-licensure preparation to practicing nurse professionals). ${ }^{[7]}$ The advancements and emergence of the genomic era has influenced and delineated fundamental healthcare issues, leading to a collective new field of study, known as omics. Omics encompasses "genomics, transcriptomics, proteomics, epigenomics, metabolomics, and mircobiomics" and "provides a comprehensive view of the biologic underpinnings of health and disease, which in the era of precision health captures the complexity of molecular biology and provides new tools for nurses to more accurately predict, prevent, diagnose, and treat disease and their related symptoms" (p51). ${ }^{[8]}$ All professional healthcare practitioners are expected to be cognizant of omics ramifications that now govern medical and nursing practices.

Studies have already established a knowledge inconsistency in genomic comprehension for the practicing nurse. A very impressive study explored the global landscape of nursing and genetics by the international nursing community, Global Genomics Nursing Alliance. ${ }^{[9]}$ Twenty-three global nurse leaders participated in this online survey that explored genomic integration in practice and education, challenges and barriers, and priorities for action in their perspective countries. ${ }^{[9]}$ Findings revealed that genomic services were primar- ily offered in specialized centers, such as newborn and prenatal screening. ${ }^{[9]}$ "Genomic literacy and infrastructure deficits were identified in both practice and education settings, with only one country (Israel) reporting a genetic/genomic knowledge and skill requirement to practice as a general nurse". ${ }^{[9]}$ Three countries (Japan, United Kingdom [UK] and US and one region [Europe]) were identified as having existing genomic competencies for nurses with a structured learning framework and five countries have a national society for genetic nurses (Japan, UK, Netherlands, Brazil and Taiwan). Certification in genetic nursing is offered by Japan and the US while Taiwan and UK certify register nurses as genetic counselors. ${ }^{[9,10]}$ The Global Genomics Nursing Alliance can provide a collegial network of resources for nursing leaders to improve genetics and genomics education. ${ }^{[9,10]}$ The only global genetic nursing organization specifically committed to genomic healthcare, education, research and scholarship is the International Society of Nurses in Genetics. ${ }^{[1]}$

A cross-sectional survey of registered nurses and midwives in Australia explored genomic knowledge utilizing the Genomic Nursing Concept Inventory (GNCI), demonstrating an overall low genomic literacy scores, and $80 \%$ of both groups selfreporting their genomic knowledge as poor or average. ${ }^{[12]}$ Another study explored genetic education, knowledge and experiences between nurses and physicians in Brazil's primary care, further demonstrating that educational and comfort level gap persists. ${ }^{[13]}$ Majority of participants (85.2\%) acknowledged receiving some genetic content during their undergraduate education, yet the majority $(77.8 \%)$ remained unprepared to deliver genomics-based health care ${ }^{[13]}$ A study of registered nurses in the US $(n=191)$ further demonstrated a limited knowledge of genomic literacy. ${ }^{[14]}$ A comparison of self-reported genomic knowledge of nurse educators and graduate degree nursing students in the US demonstrated that both groups had similar genomic knowledge levels and deficits in their ability to integrate this knowledge into practice. ${ }^{[4]}$ Overall, "the genomic resources that already exist are not readily accessible or discoverable to the international nursing community and as such are underutilized" (p53). ${ }^{[10]}$

Studies on nursing faculty and students' genomic knowledge continues to establish a genomic literacy disparity. Studies with pre-licensure baccalaureate nursing students utilizing the GNCI revealed continued gaps in genomic concept knowledge and readiness for use in practice. ${ }^{[15,16]}$ As students feel more confident with their understanding of genomics and its health implications, these practitioners will become more confident and competent in providing holistic and safe care for their patients. ${ }^{[15]}$ Self-rated studies of genetic knowledge in pre-licensure undergraduate or graduate nursing programs further demonstrates an inconsistency in 
genomic familiarity. ${ }^{[1-3,17-20]}$ Overall, there is a critical lack of genomic understanding, skill and confidence. ${ }^{[21]}$ Studies also confirmed that students felt that nurse educators need more confidence in teaching and explaining this content and faculty need to be adequately prepared to actually inform the future professional. ${ }^{[1,4]}$

\subsection{Holistic nursing}

A holistic nurse, who must also be a board-certified registered nurse, incorporates a mind-body-spiritual-culturalemotional approach that complements traditional nursing care. Holistic nurses often utilize complementary alternative modalities, such as touch and hand-mediated therapies, imagery, relaxation and mindfulness techniques, as well as aromatherapy, homeopathy, herbology and botanical treatments. These modalities can be integrated in all areas of the healthcare setting and in conjunction with traditional Western patient care. It is important to note that nurses in general are professionally trained to treat their patients holistically, meaning to participate in the healing-caring process of the whole person/family. A holistic nurse is an individual who sought additional learning and practice to further enhance their ability to engage with and care for their patients with diverse healing practices. All nurses, including holistic nurses, need to have foundational genomic knowledge to competently provide fundamental information and resources to their patients. ${ }^{[22]}$

\subsection{Implications for nursing practice}

The ever-advancing transformative art and science of nursing instills core ethos of continued personal and professional growth and development, leadership and advocacy for knowledge enhancement for self and others. Informed comprehensive nursing practice necessitates an understanding of the fundamental aspects of the previously stated core competencies, to be fully engaged in the participatory care and education of their patients. Nursing practice, policy, research and genomic knowledge and utilization of knowledge is required for this unique specialty to remain current and continue their advancement in the genomic era. ${ }^{[22]}$ Individualized personalized treatments and care based on genetic profiles requires all nurses to have specific genomic knowledge in order to facilitate optimal patient care. ${ }^{[23]}$ Genetically-based conditions and disease are the construct across this new horizon of the healthcare continuum. Nurses however have a genomic knowledge deficient leading to a diminished ability to integrate it into their practice. ${ }^{[21]}$

The relevance to practice is substantial. Nurses need to be competent to explain to patients and their families the various implications related to genetically-based conditions, screen-

Published by Sciedu Press ing and testing, treatment options, pharmacogenomics and numerous other aspects as previously stated. The "lack of genomic competency among practicing nurses is preventing nurses from adequately screening patients at risk for genetic health compromise and providing appropriate patient advocacy" (p90). ${ }^{[3]}$ Being able to integrate genomics into personalized patient-centered care can assist with an overall understanding of health, risk, disease symptomology and progression, therapeutic decision-making, new therapy options and availability and responses/implications to interventions. ${ }^{[9]}$ Nurses have a distinct ability to provide a significant and unique perspective to genomic understanding, focusing on health promotion, caring and healing, relationship dynamics between and among family, community and society as a whole. ${ }^{[2]}$ Nurses work in a variety of healing domains and patient population diversity, with patients through-out their lifespan, and must be able to implement and integrate genomic understanding at numerous phases and stages during a patients' well-being process. Facilitating synchronous personalized-centered care, health and wellness integration comprising various dimensions of an interactive relationship constitutes holistic nursing. ${ }^{[24]}$ The all-encompassing precision patient care process of nursing now must also integrate and embrace genomics/omics, yet genomic knowledge is not as present as other competencies in the repertoire of nursing care and knowledge.

\subsection{Conceptual framework}

The Diffusion of Innovations (DOI) theory provided the conceptual framework to this study, identifying the knowledge base of holistic nurses related to genomic knowledge, while indicating their comfort/confidence level and attitudes/perceptions as they integrate this knowledge into their practice. ${ }^{[25,26]}$ Identifying the holistic nurses' genomic knowledge base and those who have/have not integrated genomics into their practice may provide insight into the relevance of promoting a wider adoption of genomic knowledge. DOI theory describes different levels of engagement and its hierarchy by which new ideas and competencies/initiatives are implemented into a society or organization. ${ }^{[25,26]}$ Identifying the characteristics of nurse adopters, those who have engaged in knowledge enhancement and as such improve their confidence and comfort in integrating genomic knowledge, can provide a foundation in the continued application of genetics in nursing practice. ${ }^{[27]}$ Jenkins \& Calzone used this theory as the basis for genomic nursing program development, believing that it provided a building block for healthcare providers to translate genetics expertise into practice. ${ }^{[28]}$ The hierarchy of knowledge conceptualization is also applicable to the general public/consumer with regards to the multiple dimensions of genetic literacy, revealing a 
need for augmenting genomic education and establishing tools for future research. ${ }^{[29]}$

\section{METHOD}

Data collection occurred during 2017-2019 after Institutional Review Board approval was received. Participant inclusion criteria was being a member of the American Holistic Nurses Association (AHNA). Recruitment was achieved with the AHNA assistance with an anonymous Survey Monkey link of the Genetic and Genomic Literacy Assessment (GGLA) survey made available via their newsletter. Email blasts of the GGLA survey link to AHNA members was discussed but never occurred. The GGLA link was available through the researchers' university Survey Monkey account and managed solely by the researcher. The GGLA survey comprised three aspects: Self-Perceived Genomic Knowledge Survey; Perceptions and Attitudes about Genomics Integration into Nursing Practice Survey and the Comfort Level of Genomics Survey. A brief demographic inventory concluded the survey. Completion of the anonymous GGLA denoted consent.

\subsection{Study design}

\subsubsection{GGLA survey: Self-perceived genomic knowledge}

The GGLA was composed of the Genetic and Genomic Concepts survey ${ }^{[30]}$ and modified with additional questions related to perceptions and attitude about genomics integration and comfort level about genomics, totally 27 questions. The Genetic and Genomic Concepts (GGC), a 15-question survey, was initially utilized to evaluate the competency of US baccalaureate nurse educators' genomic knowledge. ${ }^{[30]}$ This short 15-questionnaire originated from the AACN Essentials of Baccalaureate Education for Professional Nursing Practice competencies $^{[31]}$ and the Essentials of Genetic and Genomic Nursing: Competencies, Curricula Guidelines, and Outcome Indicators, ${ }^{[32]}$ with contributions from ISONG members and expert nurse educators. Permission was granted, via email communication, to incorporate the GGC survey. ${ }^{[30]}$ Adapting the GGC influenced the researcher to develop the GGLA The GGLA, as shown in Table 1, includes the GGC genomic knowledge questions with additional questions including: seven questions exploring perception and attitude about genomic integration into nursing practice and five questions exploring the nurses' comfort level about genomics. The validity and reliability of both GGC and GGLA surveys have effectively proven to provide data on self-perceived knowledge genomics concepts. ${ }^{[1,4,30]}$

\subsubsection{Perceptions and attitudes about genomics integra- tion into nursing practice survey}

This survey, as Shown in Table 2, comprised seven questions using a 5-point Likert scale of strongly agree/agree, disagree/strongly disagree to unsure for perceptions and attitudes. Perception and attitude survey explored the importance of genomics for the nurse; importance of preparing nurses to utilize genomics; importance of teaching nurses genomics to keep nursing integral in patient/family care; does family history assessment has little value; work environment motivation; interest in taking a genomics course and importance of nurses to advocate for their patients regarding genomic healthcare issues.

\subsubsection{Comfort level of genomics survey}

Comfort level aspect comprised five questions exploring collecting family history and generating a pedigree depiction; sharing genomic knowledge in work environment; requesting additional education about genetic diseases; comfort in explaining a Mendelian inheritance pattern and comfort in teaching genomic concepts. This survey, as shown in Table 3, also utilized a five-point Likert score of strongly agree/agree comfortable, disagree/not comfortable to unsure.

\subsubsection{Statistical analysis - participant performance}

Descriptive item analysis to the self-perceived genomic knowledge questions were based on correct percentage score to each individual question. Tallies to the perceptions and attitudes about genomic integration and comfort level provided statistical understanding of these aspects. Comparison of holistic nurses' genomic literacy to the researchers' previous study on nurse educators and graduate students provided a unique perspective of practicing nurses' genomic knowledge. ${ }^{[4]}$ Given that all of these participants utilized the same GGLA survey, comparison of all findings continued to demonstrate a lack of genomic knowledge and minimal comfort.

\subsubsection{Study limitations}

As this was an In-Kind study with the AHNA for volunteer services rendered, multiple notifications were to be sent by the AHNA to all of their members via their newsletter and blast emails. Unfortunately, these activities did not fully occur and as such, there were only two main periods within the two years of this study (2017-2019) when participants responded. Hence, the significant small response rate. In addition, the sample being solely from United States participants cannot be generalizable to the population of nurses or the nursing profession globally. As this study explored self-perceived genomic knowledge, perceived versus actual genomic knowledge remains variable. ${ }^{[15]}$ Finally, the subject matter may have been intimidating to individuals leading to participants unwillingness to participate. Nevertheless, data received does confirm a gap in the genomic knowledge base of these participants and their desire to enhance their educational understanding of this material. 


\section{Results}

\subsection{Participants}

Forty-one holistic nurses were female with one male. Ages ranged from 25-70 years of age with the majority being between $41-60(63.4 \% / \mathrm{n}=26)$. The majority had only $0-10$ years in holistic nursing $(51.2 \% / \mathrm{n}=21)$ with the highest degree obtained being a Bachelor of Science in Nursing (BSN; $50 \% / \mathrm{n}=20)$. Interestingly, $97.6 \%(\mathrm{n}=40)$ did not receive genomic education within their pre-licensure baccalaureate program nor take a genomic course after graduation. This does correlate to genomics, on a global scale, not being fully immersed in pre-licensure baccalaureate nursing curricula. ${ }^{[9]}$ The majority indicated interest in exploring strategies to enhance their overall genomic understanding $(82.9 \% / \mathrm{n}=34)$ and learning how to integrate genomics into their nursing practice $(68.3 \% / \mathrm{n}=28)$.

\subsubsection{Self-perceived genomic knowledge survey/GGLA item scores for holistic nurses}

Of the 15 multiple choice questions pertaining to genomic knowledge, eight questions had over 50\% correct responses, with carrier testing having $90.2 \%(\mathrm{n}=37)$ and BRCA1 allele understanding at $89.7 \%(\mathrm{n}=35)$ having the highest correct percentages. Seven questions had under $50 \%$ correct responses with the lowest being understanding what a reciprocal translocation at $10.3 \%$ correct $(n=4)$ and interpreting inheritance pattern on a pedigree having $24.3 \%(n=9)$. As shown in Table 1, the GGLA Item Scores for Holistic Nurse, provides data for this study including data from previous study for comparison. ${ }^{[4]}$

Table 1. GGLA Item Scores for Holistic Nurse Including Data from Previous Study ${ }^{[4]}$ for Comparison. Holistic Nurse (HN; $n=41)$ Nurse Educator (NE; $n=53) R N$ Graduate Degree Students $(R N ; n=36)=$ Advanced Practice RN students $* / n=$ 31; DNP students $* / n=5$ (Item scores: $n=$ number of participants; Correct Responses with Percentages)

\begin{tabular}{llllll}
\hline Item Question & $\mathbf{H N}(\mathbf{n}=\mathbf{4 1})$ & $\mathbf{N E}^{[4]}(\mathbf{n}=\mathbf{5 3})$ & $\mathbf{R N}^{[4]}(\mathbf{n}=\mathbf{3 6})$ & $\mathbf{A P R N}^{\left[{ }^{[4]}\right.}(\mathbf{n}=\mathbf{3 1})$ & $\mathbf{D N P} *^{[4]}(\mathbf{n}=\mathbf{5})$ \\
\hline Item 1: Allele & $18(46.2 \%)$ & $26(49 \%)$ & $19(52 \%)$ & $54.84 \%$ & $40 \%$ \\
Item 2: Phenotypic polymorphisms & $20(52.6 \%)$ & $27(51 \%)$ & $28(77.8 \%)$ & $74.19 \%$ & $100 \%$ \\
Item 3: Reciprocal translocation & $4(10.3 \%)$ & $8(16 \%)$ & $9(25 \%)$ & $12.9 \%$ & $100 \%$ \\
Item 4: Autosomal recessive & $15(36.6 \%)$ & $23(45.1 \%)$ & $16(44 \%)$ & $26.6 \%$ & $40 \%$ \\
Item 5: Somatic cell mutation & $19(48.7 \%)$ & $28(54.9 \%)$ & $23(63.9 \%)$ & $70.97 \%$ & $20 \%$ \\
Item 6: Genetic testing & $21(51.2 \%)$ & $9(17.65 \%)$ & $4(11 \%)$ & $12.9 \%$ & $0 \%$ \\
Item 7: X-linked recessive & $24(61.5 \%)$ & $25(51.02 \%)$ & $18(50 \%)$ & $54.84 \%$ & $20 \%$ \\
Item 8: BRCA1 allele & $35(89.7 \%)$ & $41(82 \%)$ & $33(91.7 \%)$ & $93.55 \%$ & $80 \%$ \\
Item 9: Carrier testing & $37(90.2 \%)$ & $44(88 \%)$ & $33(91.7 \%)$ & $93.55 \%$ & $100 \%$ \\
Item 10: GINA/Health Insurance & $32(82.1 \%)$ & $43(87.76 \%)$ & $33(91.7 \%)$ & $93.55 \%$ & $100 \%$ \\
Item 11: Pregnancy DNA mutations & $18(48.6 \%)$ & $19(38 \%)$ & $14(38.9 \%)$ & $34.48 \%$ & $80 \%$ \\
Item 12: Patient history & $33(80.5 \%)$ & $43(86 \%)$ & $33(91.7 \%)$ & $93.55 \%$ & $80 \%$ \\
Item 13: Pedigree symbol & $14(37.8 \%)$ & $18(38.3 \%)$ & $26(72 \%)$ & $80 \%$ & $40 \%$ \\
Item 14: Penetrance & $24(63.2 \%)$ & $34(70.83 \%)$ & $19(52.8 \%)$ & $48.39 \%$ & $80 \%$ \\
Item 15: Interpreting pedigree & $9(24.3 \%)$ & $10(20.83 \%)$ & $8(22 \%)$ & $12.9 \%$ & $40 \%$ \\
Mean & $54.9 \%$ & $53.09 \%$ & $56 \%$ & & \\
Median & $51.2 \%$ & $51.0 \%$ & $52.4 \%$ & & \\
Standard Deviation & 22.64 & 24.31 & 26.69 & & \\
\hline
\end{tabular}

Note. Data collected from 2014-2015 ${ }^{[4]}$

\subsubsection{Perceptions and attitudes about genomics integra- tion into nursing practice}

As shown in Table 2, six of the seven questions had a majority of over $65 \%$ strongly agree/agree while one question was evenly split between strongly agree/agree and strongly disagree/disagree. Taking a genomics course would be beneficial to integrate content had the highest percentage with $87.8 \%(\mathrm{n}=36)$ agreeing with advocacy importance having $85.4 \%(\mathrm{n}=35)$. Work environment motivating the nurse to learn more about genomics had an even split between strongly agree/agree and strongly disagree/disagree, with both having $43.9 \%(n=18$ for each) and $12.2 \%(n=5)$ being unsure.

\subsubsection{Comfort level of genomics}

Majority of participants were significantly not comfortable with their genomic knowledge ( $90 \%$ or greater), as shown in Table 3 . The comfort of collecting a family history/drawing a 
pedigree and comfort in teaching genomic concepts both had How comfortable the nurse was in requesting additional $\mathrm{n}=39$ uncomfortable $(95.2 \%)$ while uncomfortable in sharing genomic knowledge was $92.5 \%(\mathrm{n}=38)$ and explaining genomic education had $34.1 \%(n=14)$ being comfortable Mendelian inheritance $(90.3 \% / \mathrm{n}=37)$ were uncomfortable. able.

Table 2. Perceptions and Attitudes about Genomics Integration into Nursing Practice

\begin{tabular}{|c|c|c|c|c|c|c|c|}
\hline Item & $\begin{array}{l}\text { Strongly } \\
\text { Agree }\end{array}$ & Agree & Disagree & $\begin{array}{l}\text { Strongly } \\
\text { Disagree }\end{array}$ & Unsure & Mean & SD \\
\hline 1. Genomics important for a holistic nurse to know & $\begin{array}{l}31.7 \% \\
(\mathrm{~N}=13)\end{array}$ & $\begin{array}{l}48.8 \% \\
(\mathrm{~N}=20)\end{array}$ & $\begin{array}{l}12.2 \% \\
(\mathrm{~N}=5)\end{array}$ & $\begin{array}{l}2.4 \% \\
(\mathrm{~N}=1)\end{array}$ & $\begin{array}{l}4.9 \% \\
(\mathrm{~N}=3)\end{array}$ & 2.00 & 0.99 \\
\hline $\begin{array}{l}\text { 2. Preparing holistic nurses to use genomics is an } \\
\text { important aspect to holistic nursing practice }\end{array}$ & $\begin{array}{l}26.8 \% \\
(\mathrm{~N}=11)\end{array}$ & $\begin{array}{l}48.8 \% \\
(\mathrm{~N}=20)\end{array}$ & $\begin{array}{l}19.5 \% \\
(\mathrm{~N}=8)\end{array}$ & $\begin{array}{l}2.4 \% \\
(\mathrm{~N}=1)\end{array}$ & $\begin{array}{l}2.4 \% \\
(\mathrm{~N}=1)\end{array}$ & 2.05 & 0.88 \\
\hline $\begin{array}{l}\text { 3. Teaching genomics important to keep holistic } \\
\text { nurses as a central partner in patient/family care }\end{array}$ & $\begin{array}{l}31.7 \% \\
(\mathrm{~N}=13)\end{array}$ & $\begin{array}{l}48.8 \% \\
(\mathrm{~N}=20)\end{array}$ & $\begin{array}{l}17.1 \% \\
(\mathrm{~N}=7)\end{array}$ & $\begin{array}{l}2.4 \% \\
(\mathrm{~N}=1)\end{array}$ & 0 & 1.90 & 0.76 \\
\hline $\begin{array}{l}\text { 4. A family history assessment with } \\
\text { genetics/genomics content (i.e.: pedigree, } 3 \\
\text { generations, age at diagnosis) have little value for } \\
\text { patient care }\end{array}$ & $\begin{array}{l}9.8 \% \\
(\mathrm{~N}=4)\end{array}$ & $\begin{array}{l}17.1 \% \\
(\mathrm{~N}=7)\end{array}$ & $\begin{array}{l}29.3 \% \\
(\mathrm{~N}=12)\end{array}$ & $\begin{array}{l}36.6 \% \\
(\mathrm{~N}=15)\end{array}$ & $\begin{array}{l}7.3 \% \\
(\mathrm{~N}=3)\end{array}$ & 3.15 & 1.09 \\
\hline $\begin{array}{l}\text { 5. The clinical environment (i.e.: hospital setting; } \\
\text { clinical setting; hospital administration) is motivating } \\
\text { me to learn more about genomics }\end{array}$ & $\begin{array}{l}19.5 \% \\
(\mathrm{~N}=8)\end{array}$ & $\begin{array}{l}24.4 \% \\
(\mathrm{~N}=10)\end{array}$ & $\begin{array}{l}26.8 \% \\
(\mathrm{~N}=11)\end{array}$ & $\begin{array}{l}17.1 \% \\
(\mathrm{~N}=7)\end{array}$ & $\begin{array}{l}12.2 \% \\
(\mathrm{~N}=5)\end{array}$ & 2.78 & 1.28 \\
\hline $\begin{array}{l}\text { 6. Taking a genetics/genomics course would help me } \\
\text { to fully integrate this content }\end{array}$ & $\begin{array}{l}41.5 \% \\
(\mathrm{~N}=17)\end{array}$ & $\begin{array}{l}46.3 \% \\
(\mathrm{~N}=19)\end{array}$ & $\begin{array}{l}7.3 \% \\
(\mathrm{~N}=3)\end{array}$ & 0 & $\begin{array}{l}4.9 \% \\
(\mathrm{~N}=2)\end{array}$ & 1.80 & 0.94 \\
\hline $\begin{array}{l}\text { 7. The importance of holistic nurses to advocate for } \\
\text { patients and society regarding ethical and legal issues } \\
\text { about genomics }\end{array}$ & $\begin{array}{l}41.5 \% \\
(\mathrm{~N}=17)\end{array}$ & $\begin{array}{l}43.9 \% \\
(\mathrm{~N}=18)\end{array}$ & $\begin{array}{l}7.3 \% \\
(\mathrm{~N}=3)\end{array}$ & 0 & $\begin{array}{l}7.3 \% \\
(\mathrm{~N}=3)\end{array}$ & 1.88 & 1.06 \\
\hline
\end{tabular}

Table 3. Comfort level of genomics $(\mathrm{N}=41)$

\begin{tabular}{|c|c|c|c|c|c|c|c|}
\hline Items & $\begin{array}{l}\text { Strongly } \\
\text { Comfortable) }\end{array}$ & Agree & Disagree & $\begin{array}{l}\text { Not } \\
\text { Comfortable }\end{array}$ & Unsure & Mean & SD \\
\hline $\begin{array}{l}\text { 1. How comfortable are you in collecting } \\
\text { a patient's family history, drawing a } \\
\text { 3-generation pedigree and analyzing that } \\
\text { pedigree? }\end{array}$ & $\begin{array}{l}2.4 \% \\
(\mathrm{~N}=1)\end{array}$ & 0 & $\begin{array}{l}19.5 \% \\
(\mathrm{~N}=8)\end{array}$ & $\begin{array}{l}75.6 \% \\
(\mathrm{~N}=31)\end{array}$ & $\begin{array}{l}2.4 \% \\
(\mathrm{~N}=1)\end{array}$ & 3.76 & 0.62 \\
\hline $\begin{array}{l}\text { 2. How comfortable are you in sharing } \\
\text { your knowledge of genomics in the } \\
\text { clinical setting? }\end{array}$ & 0 & $\begin{array}{l}4.9 \% \\
(\mathrm{~N}=2)\end{array}$ & $\begin{array}{l}26.8 \% \\
(\mathrm{~N}=11)\end{array}$ & $\begin{array}{l}65.9 \% \\
(\mathrm{~N}=27)\end{array}$ & $\begin{array}{l}2.4 \% \\
(\mathrm{~N}=1)\end{array}$ & 3.66 & 0.61 \\
\hline $\begin{array}{l}\text { 3. How comfortable are you in } \\
\text { requesting more education about genetic } \\
\text { diseases and genetic counseling? }\end{array}$ & $\begin{array}{l}22 \% \\
(\mathrm{~N}=9)\end{array}$ & $\begin{array}{l}39 \% \\
(N=16)\end{array}$ & $\begin{array}{l}26.8 \% \\
(\mathrm{~N}=11)\end{array}$ & $\begin{array}{l}7.3 \% \\
(\mathrm{~N}=3)\end{array}$ & $\begin{array}{l}4.9 \% \\
(N=2)\end{array}$ & 2.34 & 1.05 \\
\hline $\begin{array}{l}\text { 4. How comfortable are you in } \\
\text { explaining the Mendelian inheritance } \\
\text { patterns to patients (autosomal } \\
\text { dominant; autosomal recessive; X-linked } \\
\text { disorders; Mitochondrial)? }\end{array}$ & $\begin{array}{l}2.4 \% \\
(\mathrm{~N}=1)\end{array}$ & $\begin{array}{l}7.3 \% \\
(\mathrm{~N}=3)\end{array}$ & $\begin{array}{l}24.4 \% \\
(\mathrm{~N}=10)\end{array}$ & $\begin{array}{l}65.9 \% \\
(\mathrm{~N}=27)\end{array}$ & 0 & 3.54 & 0.74 \\
\hline $\begin{array}{l}\text { 5. How comfortable are you in teaching } \\
\text { the concepts of genomics to fellow } \\
\text { nurses? }\end{array}$ & $\begin{array}{l}2.4 \% \\
(\mathrm{~N}=1)\end{array}$ & 0 & $\begin{array}{l}22.0 \% \\
(\mathrm{~N}=9)\end{array}$ & $\begin{array}{l}73.2 \% \\
(\mathrm{~N}=30)\end{array}$ & $\begin{array}{l}2.4 \% \\
(\mathrm{~N}=1)\end{array}$ & 3.73 & 0.60 \\
\hline
\end{tabular}

\section{Discussion}

Current data findings unfortunately coincide with findings from previous studies (from 2005-2013) that have revealed the educational disparity in genomic knowledge and the lack of confidence and comfort in disseminating genomic content. ${ }^{[9,17,19,33-37]}$ Apparently, there has not been a major 
shift in the educational genomic literacy of the nursing profession. A significant majority of nurses are unprepared to adopt genomics into their practice whilst experiencing a lack comfort and confidence. This study provided insight into the overall genomic knowledge base of holistic nurses compared to nurse educators and advanced degree practicing registered nurses, exemplifying the deficiencies and need for additional education and resources. Comparison of participants in this study to the item scores for nurse educators and advanced degree practicing nursing students surprisingly demonstrated that some of the item questions had a higher percentage correct for the holistic nurse, which comprised $50 \%$ BSN levels compared to the nurse educator and graduate students who had advanced degrees or had a genetics course in their pre-licensure undergraduate program. ${ }^{[4]}$ For example, holistic nurses scored a higher correct percentage to questions pertaining to genetic testing, $\mathrm{X}$-linked recessive, pregnancy DNA mutations and terminology of penetrance. However, the holistic nurse scored significantly less with their understanding of reciprocal translocation, somatic cell mutation and understanding pedigree symbols. Holistic nurses (24.3\%), nurse educators $(20.83 \%)$ and practicing registered nursing advanced degree students $(52.9 \%)$ scored poorly on interpreting a pedigree depiction. These self-reported findings of nurses in genomic knowledge demonstrates limited exposure to genetic content and understanding of the material. Limited educational training leading to inadequate competency in applying this knowledge clinically can lead to significant deficiencies in patient care and patient outcomes. ${ }^{[38]}$ Safe and effective nursing care must incorporate genomic competencies ${ }^{[14]}$ and all nurses need to include this competency into their overall scope and standards of practice. It is apparent that practicing nurses, nurse educators and the students they teach, have a close educational genomic illiteracy. ${ }^{[1,4,39]}$ Incorporating genomic education into nursing curricula can enhance nurses' competency and comfort level to incorporate into patient care. ${ }^{[9,10]}$ A genetically-based condition can lead to emotional, psychological and social stress on individuals, family members, and communities. ${ }^{[40]}$ There must now be an emphasis on preparing nurses to integrate genomics into their patient-centered repertoire of personalized care, thus improving patient outcomes and the overall well-being of society and its members.

The overwhelming majority of the holistic nurses $(87.8 \%)$, nurse educators $(86.8 \%)$ and $88.8 \%$ of the practicing registered nursing advanced degree students agreed that taking a genomics course would help them to fully integrate this content into their practice. The importance of advocating for patients and society regarding ethical and legal issues about genomics was also strongly agreed upon by all participants, with $85.4 \%$ holistic nurses, $75.8 \%$ nurse educators and $100 \%$ of the practicing advanced degree students. Interestingly, holistic nurses were split in their attitude that their workplace environment motivated them to learn about genomics with $43.9 \%$ agreeing and disagreeing to this item. This attitude was found to be similar to nurse educators $(41.5 \%$ agreeing; $43.3 \%$ disagreeing) and practicing nurses (47.2\% agreeing; 50\% disagreeing). Personal and organizational characteristics can promote positive opportunities or barriers to such opportunities. ${ }^{[41]}$ Finally, the majority of holistic nurses $(65.9 \%)$ perceived that a family history assessment with genomics content (i.e.: pedigree, 3 generations, age at diagnosis) would have value for patient care as did nurse educators $(67.9 \%)$ and practicing nurses $(58.3 \%)$. Family health information is a crucial tool to ensure appropriate genomic healthcare data, thus enhancing and promoting advanced knowledge of disease process, treatment effectiveness and medication safety. ${ }^{[42]}$

The unfamiliarity of genomics and lack of confidence and comfort to discuss, explain, integrate and teach this content continues to be a relevant discrepancy in the nurses' unpreparedness during this genomic era. Nursing education has been slow to integrate genetic and genomic content into prelicensure and graduate curricula, hence, there still remains a gap in the foundational knowledge base of nursing students, practicing nurses and nursing faculty members. ${ }^{[43]}$ The nursing profession and nursing academe need to embrace genomic integration into their practice, curricula and consciousness to successfully participate in the genomicbased care of patients and families. A significant majority of holistic nurses $(75.6 \%)$ were strongly uncomfortable in collecting a patient's family history, drawing a 3-generation pedigree and analyzing that pedigree. This corresponded to the majority of nurse educators $(77.3 \%)$ and practicing nurses $(58.5 \%)$ also being somewhat to strongly uncomfortable with this ability. The majority of holistic nurses $(95.1 \%)$, nurse educators $(79.2 \%)$ and practicing nursing students $(88 \%)$ were uncomfortable sharing their knowledge of genomics in the clinical workplace setting. In addition, $90.3 \%$ holistic nurses, $83 \%$ nurse educators and $88 \%$ practicing registered nursing students were uncomfortable teaching the concepts of genomics to fellow nurses received significantly high uncomfortable responses. Addressing the deficits of genomic knowledge and competency levels can lead to improved patient healthcare outcomes, quality of patient-centered care, a decrease in healthcare costs and enhanced and improved patient safety. ${ }^{[10]}$ As confidence and comfort increases, so too will perceptions and attitude of the importance of genomic integration. Nursing, at its core, emphasizes integration of bio-psycho-social-cultural-spiritual entities to ensure effec- 
tive and efficient patient outcomes.

\section{Conclusion}

Although many recognize genomics as an important component of disease, most practitioners feel unprepared to engage with it in practice. The success of nursing practice resides with its' practitioners being fully informed and competent with all required competencies, especially if nursing is to remain prevalent within personalized healthcare. The ethical, social, and legal obligation requires all nurses to be fully knowledgeable and competent to participate in the genomic era. The first step in this process is with education. Nurses should be self-directed to enhance their genomic knowledge literacy. Clinical implications should inform strategies needed to prepare all nurses to improve their genomic knowledge. There are numerous educational resources available for self-directed learning. ${ }^{[22,23,44]}$ Offering genomic in-services, workshops and webinars providing the basic foundational knowledge could provide guidance in meeting this educational need. It is vital and incumbent for the nursing profession to continue to bestow the foundations of genomics ensuring practitioners adequately prepared to impart genetically-sound guidance and advocacy.

\section{ACKNOWLEDGEMENTS}

The author would like to thank all participants and the American Holistic Nurses Association for their support.

\section{CONFLICTS OF INTEREST DisClosure}

The author declares that there is no conflict of interest.

\section{REFERENCES}

[1] Sharoff L. Three-Year Assessment of One Pre-Licensure Cohort of Baccalaureate Nursing Students' Attitude, Comfort and Knowledge of Genomics. J of Nursing Education and Practice. 2017; 7(12): 114-122. https://doi.org/10.5430/jnep.v7n12p114

[2] Sharoff L. Perceived Genetic Knowledge in Pre-Licensure Nursing Students. Journal of Nursing Education and Practice. 2017; 7(2): 10-17.

[3] Camak D. Increasing importance of genetics in nursing. Nurse Educ Today. 2016; 44: 86-91. PMid:27429334 https ://doi .org/10.1 $016 / j$.nedt .2016 .05 .018

[4] Sharoff L. Comparison of Perceived Genetic Knowledge of Nurse Educators and Graduate Degree Nursing Students. J of Nursing Education and Practice. 2017b; 7(9): 67-71. https://doi .org/10.5 430/jnep.v7n9p67

[5] Jenkins J, Calzone K, Caskey S, et al. Methods of genomic competency integration into practice. J of Nursing Scholarship. 2015; 47(3): 200-210. PMid:25808828 https://doi.org/10.1111/jn u. 12131

[6] National Human Genome Research Institute. An overview of the human genome project. Available from: https ://www.genome.g ov/human-genome-project

[7] National Coalition for Health Professional Education in Genetics. Core Competencies in Genetics Essential for All Health-Care Professionals. 2007. Available from: https://www.ncbi.nlm.nih.gov /books/NBK115543/

[8] Regan M, Engler M, Coleman B, et al. Establishing the genomic knowledge matrix for nursing science. $\mathrm{J}$ of Nursing Scholarship 2019; 51(1): 50-57. PMid:30272391 https://doi.org/10.111 $1 /$ jnu. 12427

[9] Calzone K, Kirk M, Tonkin E, et al. The global landscape of nursing and genomics. J of Nursing Scholarship. 2018; 50(3): 1-8. PMid:29608246 https://doi.org/10.1111/jnu. 12380

[10] Calzone K, Kirk M, Tonkin E, et al. Increasing nursing capacity in genomics: Overview of existing global genomics resources. Nurse Education Today. 2018a; 69: 53-59. PMid:30007148 https : //doi.org/10.1016/j.nedt.2018.06.032

[11] ISONG. International Society of Nurses in Genetics. https : //www . isong.org/
[12] Wright H, Zhao L, Birks M, et al. Genomic literacy of registered nurses and midwives in Australia: A cross-sectional survey. J of Nursing Scholarship. 2019; 51(1): 40-49. PMid:30367730 https://doi.org/10.1111/jnu. 12440

[13] Lopes-Junior L, Carvalho Junior C, Evangelista de Faria Ferraz $\mathrm{V}$, et al. Genetic education, knowledge and experiences between nurses and physicians in primary care in Brazil: A cross-sectional study. Nursing \& Health Science. 2016; 19: 66-74. PMid:27510609 https://doi.org/10.1111/nhs. 12304

[14] Rogers M, Lizer S, Doughty A, et al. Expanding RN scope of knowledge - Genetics/Genomics: The new frontier. J of Nurses in Professional Development. 2017; 33(2): 56-61. PMid:28252482 https://doi.org/10.1097/NND.0000000000000340

[15] Munroe T, Loerzel V. Assessing nursing students' knowledge of genomic concepts and readiness for use in practice. Nurse Educator. 2016; 41(2): 86-89. PMid:26312820 https://doi.org/10.109 $7 /$ NNE. 0000000000000210

[16] Ward L, Purath J, Barbosa-Leiker C. Assessment of Genomic Literacy Among Baccalaureate Nursing Students in the United States: A Feasibility Study. Nurse Educator. 2016; 41(6): 313-318. PMid:27232369 https://doi.org/10.1097/NNE.0000000000000272

[17] Maradiegue A, Edwards QT, Seibert D, et al. Knowledge, perceptions and attitudes of advanced practice nursing students regarding medical genetics. J of the American Academy of Nurse Practitioners. 2005; 17: 472-479. PMid:16248880 https://doi.org/10.1111/j.17 $45-7599.2005 .00076 \cdot \mathrm{x}$

[18] Kiray B, Tomatir A, Kuzu Kurban K, et al. Nursing Students' SelfReported Knowledge of Genetics and Genetic Education. Public Health Genomics. 2009; 12(4): 225-232. PMid:19182476 https : //doi.org/10.1159/000197972

[19] Dodson C, Lewallen L. Nursing students' perceived knowledge and attitude towards genetics. Nurse Educ Today. 2011; 31(4): 333-339. PMid:20678829 https://doi.org/10.1016/j .nedt. 2010.07 .001

[20] Hsiao C, Riper M, Lee S, et al. Taiwanese Nursing students' perceived knowledge and clinical comfort with genetics. J of Nursing Scholarship. 2011; 43(2): 125-132. PMid:21605316 https: //doi.org/10.1111/j.1547-5069.2011.01389.x 
[21] Anderson G, Alt-White A, Schaa K, et al. Genomics in nursing education and practice: Measuring competency. Worldviews Evidence-Based Nursing. 2015; 12(3): 162-175. PMid:26052963 https://doi.org/10.1111/wvn.12096

[22] Sharoff L. Holistic Nursing in the Genetic/Genomic Era. J of Holistic Nursing. 2016; 34(2): 146-153. PMid:26025092 https: //doi.org/10.1177/0898010115587401

[23] Montgomery S, Brouwer W, Everett P, et al. Genetics in the clinical setting. American Nurse Today. 2017; 12(10): 10-16. Available from: https://www.americannursetoday.com/genetic s-clinical-setting/

[24] Erickson H, Erickson M, Sandor MK, et al. The holistic worldview in action: Evolution of holistic nurses' certification programs. J of Holistic Nursing. 2013; 31(4): 303-313. PMid:23958825 https : //doi.org/10.1177/0898010113499975

[25] Rogers, EM. Diffusion of Innovation. Free Press; New York: 1962.

[26] Rogers EM. Diffusion of Innovation, 5th Ed. Free Press; New York: 2003.

[27] Andrews V, Tonkin E, Lancastle D, et al. Using the Diffusion of Innovations theory to understand the uptake of genetics in nursing practice: Identifying the characteristics of genetic nurse adopters. J of Advanced Nursing. 2013; 70(4): 878-893. PMid:24102681 https://doi.org/10.1111/jan.12255

[28] Jenkins J, Calzone K. Establishing the essential nursing competencies for genetics and genomics. J of Nursing Scholarship. 2007; 39(1): 1016. PMid:17393960 https://doi.org/10.1111/j.1547-5069. $2007.00137 . x$

[29] Abrams L, McBride C, Hooker G, et al. The many facets of genetic literacy: Assessing the scalability of multiple measures for broad use in survey research. PLoS One. 2015; 10(10): e0141532. PMid:26510161 https://doi .org/10.1371/journal.pone.0 141532

[30] DeSevo M. Competency of nurse educators in genetics/genomics knowledge. J of Nursing Educ and Practice. 2013; 3(1): 123-129. https://doi.org/10.5430/jnep.v3n1p123

[31] American Association of Colleges of Nursing. The Essentials of Baccalaureate Education for Professional Nursing Practice. Washington, DC: American Association of Colleges of Nursing. 2008. Available from: www. aacnnursing.org/portals/42/publications/ba ccessentials08.pdf

[32] Consensus Panel on Genetic/Genomic Nursing Competencies. Essentials of Genetic and Genomic Nursing: Competences, Curricula Guidelines, and Outcome Indicators. 2008. Available from https://www.genome.gov/Pages/Health/HealthCare ProvidersInfo/Grad_Gen_Comp.pdf

[33] Seibert D, Edwards Q, Maradiegue A. Integrating genetics into advanced practice nursing curriculum: Strategies for success. Commu- nity Genetics. 2007; 10:45-51. PMid:17167251 https://doi.or g/10.1159/000096278

[34] Vural B, Tomatir A, Kurban N, et al. Nursing students' self-reported self-reported knowledge of genetics and genetic education. Public Health Genomics. 2009; 12(4): 225-232. PMid:19182476 https : //doi.org/10.1159/000197972

[35] Skirton H, O'Connor A, Humphreys A. Nurses' competence in genetics: A mixed method systematic review. J of Advanced Nursing. 2012; 68(11): 2387-2398. PMid:22607038 https://doi.org/10 $.1111 / j .1365-2648.2012 .06034 . x$

[36] Calzone K, Jenkins J, Yates J, et al. Survey of nursing integration of genomics into nursing practice. J of Nursing Scholarship. 2012; 44(4): 428-436. PMid:23205780 https://doi.org/10.1111/j. 1547-5069.2012.01475.x

[37] Calzone K, Jenkins J, Culp S, et al. National nursing workforce survey of nursing attitudes, knowledge and practice in genomics. Personalized Medicine. 2013; 10(7): 719-728. PMid:24363765 https://doi.org/10.2217/pme.13.64

[38] Williams J, Katapodi C, Starkweather A, et al. Advanced nursing practice and research contributions to precision medicine. Nursing Outlook. 2016; 64(2): 117-123. PMid:26712384 https ://doi.or $\mathrm{g} / 10.1016 / \mathrm{j}$. outlook. 2015.11.009

[39] Read C, Ward L. Misconceptions about genomics among nursing faculty and students. Nurse Educator. 2018; 43(4): 196-200. PMid:28858953 https://doi.org/10.1097/NNE. 0000000000 000444

[40] Hu J, Yu L, Modanloo S, et al. A theoretical framework for interaction of nursing discipline with genetics and genomics. International J of Nursing Sciences. 2018; 5(4): 336-342. PMid:31406845 https://doi.org/10.1016/j.ijnss.2018.08.004

[41] Alhakami I, Baker O. Exploring the factors influencing nurse's work motivation. J of Nursing \& Care. 2018; 1(1): 1-12. https: //doi.org/10.33552/IJNC. 2018.01.000503

[42] Hickey K, Katapodi M, Coleman B, Reuter-Rice K, Starkweather, A Improving utilization of the family history in the electronic health record. J Nurs Scholarship. 2017; 49(1): 80-86. PMid:28094908 https://doi.org/10.1111/jnu.12259

[43] Aiello L. Genomics education: Knowledge of nurses across the profession and integration into practice. Clinical Journal of Oncology Nursing. 2017; 21(6): 747-753. PMid:29149120 https: //doi.org/10.1188/17.CJON.747-753

[44] Institute of Medicine (IOM). Improving genetics education in graduate and continuing health professional education: Workshop summary. Washington, DC; The National Academies Press. 2015. Available from: https://www.nap.edu/read/18992/chapter/1\#i i 